\title{
Hypocrétines et orexines ne font qu'un : découvertes "simultanées" de deux nouveaux peptides orexigènes
}

La course à l'isolement de nouveaux peptides impliqués dans le contrôle de la prise alimentaire prend une tournure de plus en plus polémique, où la Big Science des compagnies pharmaceutiques et la recherche académique s'affrontent. Au mois de janvier de cette année paraît un article dans Proceedings of the National Academy of Sciences (USA) concernant une étude collaborative dirigée par J.G. Sutcliffe (The Scripps Clinic, La Jolla). Faisant suite à l'identification d'ARNm exprimés sélectivement dans l'hypothalamus par une méthode soustractive de $\operatorname{tag} P C R$ [1], les auteurs décrivent la caractérisation structurale et fonctionnelle d'un de ces ARNm codant pour le précurseur de deux nouveaux peptides [2]. Les études de localisation cérébrale démontrent l'expression de ces peptides dans l'hypothalamus latéral avec une distribution ressemblant de manière troublante aux neurones à MCH (melanin-concentrating hormone), un neuropeptide impliqué dans le contrôle de la prise alimentaire $(\mathrm{m} / \mathrm{s}$ $n^{\circ}$, vol. $12, p .625$ ). Sur la base de cette expression hypothalamique et d'une analogie partielle («ténue» serait plus approprié) avec la sécrétine de rat, les malheureux peptides se voient affublés d'un nom certes consensuel mais pour le moins évocateur (provocateur?) d'hypocretins (rebaptisés hypocrétines en français) [2]. Un malheur n'arrivant jamais seul, un mois plus tard une collaboration conduite par M. Yanagisawa et comprenant des chercheurs de l'Université du Texas et de la compagnie pharmaceutique Smithkline Beecham publie dans Cell une étude exhaustive sur de nouveaux peptides, nommés orexins (orexines en français) sur la base de leur propriété orexigène révélée dans cette publication [3]. La méthode d'isolement de ces orexines est particulièrement impressionnante et illustrative des stratégies industrielles mises en œuvre pour identifier de nouvelles molécules susceptibles d'avoir un interêt pharmaceutique. En effet, les auteurs ont testé systématiquement des extraits peptidiques de différents organes de rat sur des cellules rénales humaines transfectées avec des gènes codant pour des récepteurs "orphelins » couplés aux protéines G (RCPG) en suivant l'induction du $\mathrm{Ca}^{2+}$ intracellulaire par les fractions peptidiques purifiées en HPLC. En criblant de la sorte plus de 50 récepteurs «orphelins» l'un d'entre eux va retenir leur attention et conduire à la purification de nouveaux neuropeptides. Là encore deux peptides sont caractérisés et le clonage de l'ADNc correspondant révèle que ces peptides proviennent d'un précurseur unique exprimé sélectivement dans l'hypothalamus latéral de rat, aire cérébrale impliquée de longue date dans la régulation de la prise alimentaire. Pour vérifier cette hypothèse, les auteurs ont administré en intracérébroventriculaire plusieurs doses de ces peptides nommés orexines A et $B$. Le résultat est frappant: les rats prennent 3 à 6 fois plus de nourriture que les témoins, et cela pendant plusieurs heures après une injection unique. L'effet de l'orexine A, plus fort que celui de l'orexine $\mathrm{B}$, est moins puissant mais plus durable que l'effet orexigène bien connu du NP-Y $(m / s$ $n^{\circ}$, vol. 12, p. 117). En outre, l'ARN messager de la pré-pro-orexine est nettement augmenté par le jeûne, comme l'ARN messager du NP-Y. Cela suggère que les orexines jouent effectivement un rôle dans la régulation physiologique de la prise alimentaire. Elles rejoignent ainsi la cohorte des neuropeptides impliqués dans l'homéostasie énergétique (m/s $n^{\circ} 4$, vol. 14, p.496). Petit détail, il n'est nullement fait mention dans cette étude du fait que les orexines et les hypocrétines ne forment qu'une seule et même famille de peptides... les séquences des $\mathrm{ADNc}$ et des peptides s'avérant identiques. La quasisimultanéité des publications pourrait expliquer cet oubli. Cependant, la structure des hypocrétines, leur localisation cérébrale et leurs effets supposés dans le contrôle de l'appétit et de la thermogenèse étaient présentés dès octobre 1997 par J.G. Sutcliffe et T.S. Kilduff lors d'une cession de Posters mémorable au Congrès des Neurosciences Américaines. Plus inexplicable est l'absence totale d'une quelconque référence aux travaux sur les hypocrétines quand il est fait état de la «découverte» des orexines dans un article de la rubrique Research News paru fin février dans Science [4]. L'histoire de cette nouvelle famille de peptides vient à peine de débuter que déjà les orexines A et B (exit les hypocrétines) sont disponibles dans les catalogues de Phoenix Pharmaceuticals Inc. Nul doute que la caractérisation complète des gènes hypocrétines/ orexines ainsi que l'étude de leur régulation dans des modèles d'obésité et divers états pathologiques sont en cours sinon en voie d'achèvement. De même, les récepteurs des orexines ayant trouvé une place de choix dans l'aristocratie des RCPG il est certain que l'isolement d'antagonistes non peptidiques devrait suivre rapidement. Le chemin sera plus long pour savoir si ces molécules seront efficaces dans le traitement de l'obésité mais, quand des millions de dollars sont en jeu, on peut prédire un bel avenir à ces faux jumeaux issus du mariage fécond d'un savoir-faire technologique et d'une maîtrise consommée des médias scientifiques.

J.L.N.

1. Gautvik KM, De Lecea L, Gautvik VT, Danielson PE, Tranque P, Dopazo A, Bloom FE, Sutcliffe JG. Overview of the most prevalent hypothalamus-specific mRNAs, as identified by directional tag PCR subtraction. Proc Natl Acad Sci USA 1996; 93: 8733-8.

2. De Lecea L, Kilduff TS, Peyron C, Gao XB, Foye PE, Danielson PE, et al. The hypocretins hypothalamus-specific peptides with neuroexcitatory activity. Proc Natl Acad Sci USA 1998; 95: 322-7.

3. Sakurai T, Amemlya A, Ishil M, Matsuzaki I, Chemelli RM, et al. Orexins and orexin receptors: a family of hypothalamic neuropeptides and G protein-coupled receptors that regulate feeding behavior. Cell 1998; 92: 573-85.

4. Barinaga M. New appetite-boosting peptides found. Science 1998; 279 : 1134. 